\title{
SURFACE HARDNESS EVALUATION OF A THERMOPLASTIC NYLON DENTURE BASE MATERIAL
}

\author{
Mohamed Shatta* , Magdy Badawy**, Diab Haddad**
}

\begin{abstract}
Objective: This study was conducted to evaluate surface hardness of a thermoplastic nylon denture base material and comparing it with conventional heat cured acrylic resin. Material and methods: Two different types of commercially available denture base materials were used in this study. Group I: Heat cured acrylic resin denture base material. Group II: Thermoplastic nylon denture base material. Specimens of $(65 \mathrm{~mm}$ X $10 \mathrm{~mm}$ X $2.5 \mathrm{~mm})$ length, width and thickness, were tested using Digital Display Vicker`s microhardness tester. Results: It was found that acrylic resin group recorded statistically non-significant higher Vickers hardness mean value $(33.591 \pm 1.850 \mathrm{HV})$ than Thermoplastic nylon group $(31.331 \pm 2.5 \mathrm{HV})$ as indicated by unpaired t-test $(\mathrm{P}=0.0818>$ 0.05). Conclusion : Thermoplastic material is less than the conventional one, in terms of surface hardness..
\end{abstract}

KEYWORDS: Thermoplastic resin, acrylic resin, complete denture, surface hardness.

\section{INTRODUCTION}

Denture base is a part of dentures that rest on the foundation areas and to which teeth are attached to replace the entire dentition and associated structures of both maxilla and mandible ${ }^{(1)}$.

The denture base is characterized by having variable functions, such as; attaching the prosthetic teeth of both the complete denture and removable partial denture. Also, transferring the heavy occlusal forces to the abutment teeth in toothtissue supported removable partial dentures (RPDs) and to the denture foundation area in the mucosa borne. Furthermore, replacing the missing alveolar tissue in bulk and appearance, providing bracing, retention and direct-indirect retention for RPDs and complete denture are considered as additional uses of the denture base ${ }^{(2)}$.

Denture base materials can be classified into two main types: metallic denture base material and nonmetallic denture base materials.

Acrylic resin is used in a wide variety of dental applications and has exhibited excellent biocompatibility when used in its polymerized form $^{(3)}$. Acrylic resin is the most commonly used denture base that is composed of polymethyl methacrylate (PMMA), which was introduced as a denture base material in 1937. It is a clear glasslike polymer; manufacturers incorporate pigments and opacifiers in order to produce a more tissue-like denture base ${ }^{(4)}$.

\footnotetext{
* Assistant Lecturere, Removable Prosthodontic Department, Faculty of Dental Medicine, Boys, Al-Azhar University , Cairo.

** Professor, Department of Removable Prosthodontics, Faculty of Dental Medicine, Boys, Al-Azhar University, Cairo
}

- Corresponding author: mohamedshata.209@azhar.edu.eg

DOI: $10.21608 /$ ajdsm.2020.34761.1079 
Since the introduction of acrylic resin as a denture base material, it was the most used denture base material, due to the superiority of acrylic resin properties. Also, other polymers as nylon, polycarbonates were used to a limited extent ${ }^{(5)}$.

The potential alternative materials to PMMA are the polycarbonates and the nylon denture base resins. Of this nylon is the generic name for certain types of thermoplastic polymers belonging to the class polyamides. These polyamides are produced by the condensation reaction between a diamine and a dibasic $\operatorname{acid}^{(6)}$.

Flexible resins were initially developed for the construction of provisional prosthesis, such as immediate RPD's. They are indicated for the construction of RPD's, mainly for anterior retention where esthetics is required. This is because of its translucency and a natural appearance without laboratory characterization. Furthermore, the flexibility of these materials prevent prosthesis from being fractured. It also adds to patient comfort as it is light in weight ${ }^{(7)}$.

Thermoplastic resins have many advantages over conventional powder or liquid resin systems. They have high flexural and impact strength, flexibility, transparency, high creep resistance, fatigue endurance, excellent wear characteristics and solvent resistance, low water sorption, with no or little residual monomer, and also no porosity, less biologic material build-up and less odor and stains and show higher dimensional and color stability. They are free of metal with a microcrystalline structure, which makes finishing and polishing easier as for acrylic resins ${ }^{(8)}$.

This new-generation nylon-based thermoplastic material has a predictable long-term performance. It is stable in nature and provides resistance to polymer unzipping. It also has reduced allergic reactions, and decreased stress on abutment teeth, high creep resistance and fatigue endurance along with the excellent wear characteristics and solvent resistance $^{(9)}$.
Though masticatory efficiency and performance were found to be better for patient's dentures made with Poly-methyl methacrylate (PMMA), a statistically significant number of patients reported that the flexible dentures were more satisfying than the conventional dentures ${ }^{(10)}$.

\section{MATERIALS AND METHODS}

\section{A. Specimen preparation:}

Two different types of commercially available denture base materials were used in this study.

Group I: Heat cured acrylic resin denture base material (Vertex ${ }^{\mathrm{TM}}$ Rapid Simplified, Vertex-Dental B.V. Headquarters The Netherlands).

Group II: Thermoplastic nylon denture base material (Dentiflex, Roko dental system, Poland.

A total of 20 samples were prepared for the current study, 10 specimens in each group were used to evaluate surface hardness.

Rectangular shaped samples pattern of $65 \mathrm{~mm}$ x $10 \mathrm{~mm} \times 2.5 \mathrm{~mm}$, length, width and thickness, respectively, were constructed from a metal mold to test surface hardness. Specimens were fabricated were prepared following the manufacturer's recommendations, then finished and polished accordingly; specimens then underwent the testing procedures.

\section{B. Surface Hardness evaluation:}

Samples were tested using Digital Display Vicker's microhardness tester (Model HVS-50 Vickers Hardness Tester, China) with a Vickers diamond indenter and a 20X objective lens.

The test was performed under load $25^{\prime} \mathrm{g}$ for 10 seconds, figure (1). Three indentations were equally placed over a circle and not closer than $0.5 \mathrm{~mm}$ between the adjacent indentations on the surface of each samples. The diagonals length of the indentations were measured by built in scaled microscope and Vicker`s values were converted into micro-hardness values which was expressed in HV. 
Micro-hardness and was obtained using the following equation: $\mathrm{HV}=1.854 \mathrm{P} / \mathrm{d} 2$

$\mathrm{HV}=$ Vickers hardness in $\mathrm{Kgf} / \mathrm{mm} .2$

$\mathrm{P}=$ load in Kgf.

$\mathrm{d}=$ the length of the diagonals in $\mathrm{mm}$.

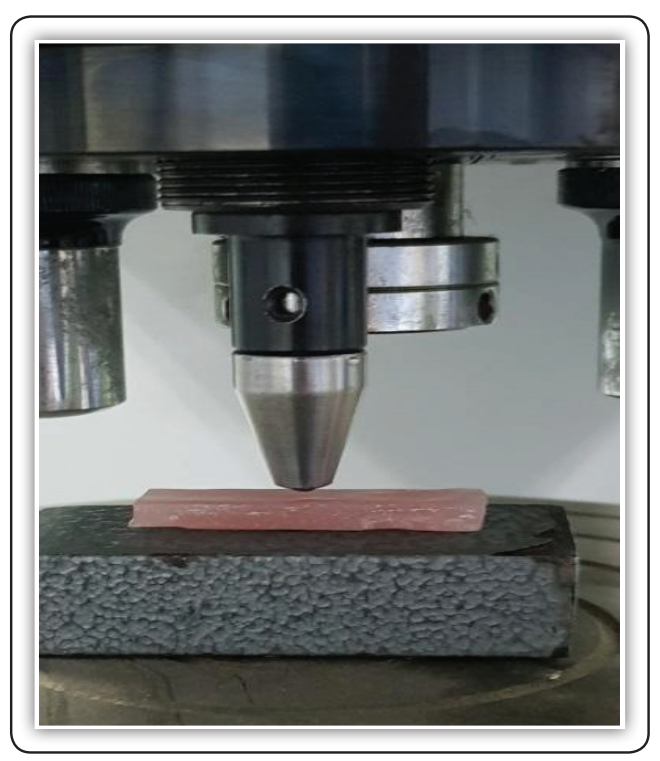

FIG (1) Vickers Micro-hardness Tester

The resulting data were collected and tabulated by using Microsoft Excel and statistically analyzed by using Statistical Package for Social Science (SPSS) ® Version 2.0.

\section{RESULTS}

A value of $\mathrm{P}<0.05$ was considered statistically significant. Continuous variables were expressed as the mean and standard deviation. After homogeneity of variance and normal distribution of errors had been confirmed, student t-test was done for compared pairs.

Descriptive statistics of Vickers hardness (HV) showing mean, standard deviation (SD), minimum, maximum and $95 \%$ confidence intervals (low and high) values for both groups are summarized in table (1) and graphically drawn in figure (2).

It was found that the Vickers hardness mean $\pm \mathrm{SD}$ values recorded for acrylic resin group was (33.591 $\pm 1.850 \mathrm{HV})$. Meanwhile the Vickers hardness mean \pm SD values recorded for thermoplastic nylon group was $(31.331 \pm 2.5 \mathrm{HV})$.

It was found that Acrylic resin group recorded statistically non-significant higher Vickers hardness mean value $(33.591 \pm 1.850 \mathrm{HV})$ than Thermoplastic nylon group $(31.331 \pm 2.5 \mathrm{HV})$ as indicated by unpaired t-test $(\mathrm{P}=0.0818>0.05)$ as shown in table (2) and figure (2).

TABLE (1 ) Descriptive statistics of Vickers hardness results (Mean values \pm SDs) for both groups

\begin{tabular}{|c|c|c|c|c|c|c|}
\hline \multirow{2}{*}{ Variables } & \multirow{2}{*}{ Mean \pm SD } & \multirow{2}{*}{ Min. } & \multirow{2}{*}{ Max. } & \multicolumn{2}{c|}{$95 \%$ CI } \\
\cline { 5 - 7 } & & & & Low & High \\
\hline \multirow{2}{*}{ Groups } & Conv. acrylic resin & $33.591 \pm 1.850$ & 31.550 & 35.862 & 31.88 & 35.301 \\
\cline { 2 - 7 } & Thermoplastic Nylon & $31.331 \pm 2.5$ & 31 & 35.1 & 28.9 & 33.6 \\
\hline
\end{tabular}

TABLE (2) Comparison of Vickers hardness results (Mean values SDs) for both groups

\begin{tabular}{|c|c|c|c|}
\hline \multicolumn{2}{|c|}{ Variables } & Mean \pm SD & P value \\
\hline \multirow{3}{*}{ Groups } & Acrylic resin & $33.591 \pm 1.850$ & \multirow{2}{*}{$0.0818 \mathrm{~ns}$} \\
\cline { 2 - 3 } & Thermoplastic Nylon & $31.331 \pm 2.5$ & \\
\hline
\end{tabular}

*; significant $(p<0.05)$ ns; non-significant $(p>0.05)$ 


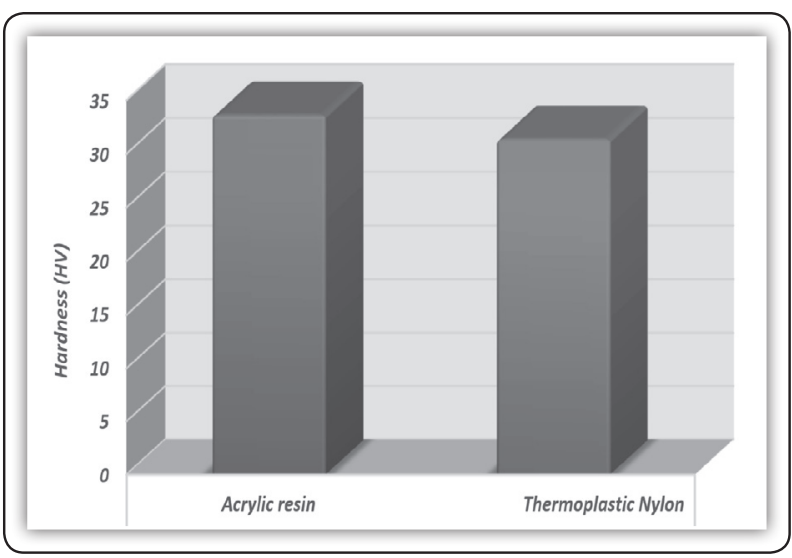

FIG (1) Vickers hardness mean values for both groups .

\section{DISCUSSION}

Surface hardness was tested using Digital Display Vicker`s micro hardness tester after proper finishing and polishing of specimens. This was to obtain flat and smooth mirror like surface for equal distribution of load without causing any scratches to guarantee accurate measurements. Surface hardness test number is highly essential as it is used to reveal the resistance of material to scratching .

The flexible cured acrylic resin showed the higher insignificant mean values than conventional acrylic resin. This was related to difference in amount of both residual monomer and porosity ${ }^{(11)}$.

The results of this study has been in accordance with Shah et al. ${ }^{(12)}$ who proved that flexible resins displayed less stiffness, and surface hardness than PMMA denture base resin. Moreover, explained that mechanical properties of the acrylic resin denture base microwave polymerized depend both on both the exposure time . From the appropriate selection of power and time of curing of the resin it is possible to obtain the best mechanical properties.

On the other hand, Oliveira et al. ${ }^{(13)}$ mentioned that there were no significant differences in the surface hardness when compared between conventional and flexible cured acrylic resin by using Shimadzu hardness tester.

\section{CONCLUSION}

This study concluded that thermoplastic material was less surface hardness than the conventional PMMA.

\section{REFERENCES}

1. Academy of Prosthodontic terms 2009: Glossary of Prosthodontic terms. 9th ed.J Prosthet Dent 105:213-282.

2. Lai C.P., Tsaia M.H., Chena M., Changb H.S. and Tay H.H. 2004: Morphology and properties of denture acrylic resins cured by microwave energy and conventional water bath Dental Materials 20: 133-141.

3. Virendra B. 2004: Contemporary dental materials, Chapter 6; Polymers and prosthodontic resins. Oxford, University press. pp 42-56

4. Mc Cabe J.F. and Walls A.W 2002: Applied dental materials. 8th ed. Chapter 13; Denture base polymers. Black well science Ltd. London. 96-106.

5. Kumar M.V., Bhagath S. and Jei J.B. 2010: Historical interest of denture base materials. University Journal of Dental Science. 1:103-105.

6. Rueggeberg 2002: From vulcanite to vinyl, a history of resins in restorative dentistry, J prosthetic dent 87:364-379.

7. Mumcu E., Ciligir A., Gencel B. and Sulun T. 2011: Flexural properties of a light-cure and self-cure denture base materials compared to conventional alternatives. J Adv. Prosthodont.3:136-139.

8. Mc Cabe J.F. and Walls A.W 2002: Applied dental materials. 8th ed. Chapter 13; Denture base polymers. Black well science Ltd. London. 96-106.

9. Vergani C.E.; Seo, Ganzarolli S. M., De Mello J. A. and DelBel A. A. 2007: Internal adaptation and some physical properties of methacrylate-based denture base resins polymerized by different techniques. J Biomed Mater Res B Appl Biomater 82, 169-173.

10. Academy of Prosthodontic terms 2009: Glossary of Prosthodontic terms. 9th ed.J Prosthet Dent 105:213-282.

11. Craig R.G. and Powers J.M. 2002: Restorative Dental Materials11th ed. by Mosby Inc. St .Louis; Missouri.262-265.

12. Shah J, Bulbule N, Kulkarni S, Shah R, Kakade D. Comparative evaluation of sorption, solubility and microhardness of heat cure polymethylmethacrylate denture base resin \& flexible denture base resin. J Clin Diagn Res.2014; $8(8): 1-4$

13. Oliveira R, Nogueira F, Mattos B. Porosity, residual monomer and water sorption of conventional heat-cured, and cross-linked acrylic resins. Clin Lab Res Dent. 2014; 20(3):137-44. 